\title{
Variability and changes of Arctic sea ice draft distribution - submarine sonar measurements revisited
}

\author{
A. Oikkonen ${ }^{1}$ and J. Haapala ${ }^{2}$ \\ ${ }^{1}$ University of Helsinki, Department of Physics, P.O. Box 48, 00014 University of Helsinki, Finland \\ ${ }^{2}$ Finnish Meteorological Institute, Helsinki, Finland
}

Received: 21 December 2010 - Published in The Cryosphere Discuss.: 12 January 2011

Revised: 16 September 2011 - Accepted: 27 September 2011 - Published: 24 October 2011

\begin{abstract}
Changes in the mean sea ice thickness and concentration in the Arctic are well known. However, quantitative information about changes in the ice thickness distribution and the composition of the pack ice is lacking. In this paper we determine the ice draft distributions, mean and modal thicknesses, and their regional and seasonal variability in the Arctic for the time period 1975-2000. We compare characteristics of the Arctic pack ice for the years 1975-1987 and 1988-2000. These periods represent different large-scale atmospheric circulation modes and sea ice circulation patterns, most evident in clearly weaker Beaufort Gyre and stronger as well as westward shifted Transpolar Drift during the later period. The comparison of these two periods reveals that the peak of sea ice draft distributions has narrowed and shifted toward thinner ice, with reductions in both mean and modal ice draft. These noticeable changes are attributed to the loss of thick, mostly deformed ice. Springtime, loss of ice volume with draft greater than $5 \mathrm{~m}$ exceeds $35 \%$ in all regions except the Nansen Basin, with as much as $45 \%$ or more at the North Pole and in the Eastern Arctic. Autumn volume reduction, mostly of deformed ice, exceeds $40 \%$ in the Canada Basin only, but is above $30 \%$ also in the Beaufort and Chukchi Seas. During the later period, the volume of ice category consisting thin, mostly level first-year ice, is clearly larger than during the former period, especially in the spring. In the Beaufort Sea region, changes in the composition of ice cover have resulted in a shift of modal draft from level multiyear ice draft range to values of level first-year ice. The regional and seasonal variability of sea ice draft has decreased, since the thinning has been most pronounced in regions with the thickest pack ice (the Western Arctic), and during the spring (0.6-0.8 $\mathrm{m}$ per decade).
\end{abstract}

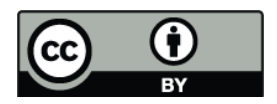

Correspondence to: A. Oikkonen (annu.oikkonen@helsinki.fi)

\section{Introduction}

The Arctic Ocean exhibits large climate variations on a time scale of decades. This variability is largely driven by the large-scale atmospheric circulation, which affects meridional heat and moisture transport from the mid-latitudes to the Arctic region and, as a consequence, alters the surface heat balance of the Arctic Ocean. Another, perhaps more significant, effect is that sea ice and ocean surface circulation patterns are modified in accordance with the atmospheric changes.

The state of the atmospheric circulation is commonly described by the empirical orthogonal function (EOF) of the surface air pressure field. The first EOF is called the Arctic Oscillation (AO) or Northern Annular Mode (Thompson and Wallace, 1998). This mode is related to the magnitude of the zonal circulation (Rigor et al., 2002; Zhang et al., 2000). The second mode is called the Dipole Anomaly (DA) (Wu et al., 2006; Watanabe et al., 2006). The DA is a measure of the strength of an atmospheric meridional circulation from the Pacific sector to the North Atlantic. Wu et al. (2006) state that the influence of the DA on winter sea ice motion is greater than that of the AO, especially in the central Arctic basin, and north of Fram Strait. During its positive phase the DA has a particularly strong effect on the ice conditions, since in addition to the strengthening of the transpolar drift, and export of sea ice from the Arctic Ocean through Fram Strait, it also enhances an inflow of Pacific water into the Arctic.

While many papers have focused on sea ice changes and the relationship between the atmospheric circulation and sea ice conditions (e.g. Hilmer and Lemke, 2000; Zhang et al., 2000; Holloway and Sou, 2002; Makshtas et al., 2003; Bitz and Roe, 2004; Rothrock and Zhang, 2005; Kwok, 2009), analyses have been mostly limited to considering mean sea ice thickness, concentration, or drift. However, the state of the pack ice is best characterized by the sea ice thickness

Published by Copernicus Publications on behalf of the European Geosciences Union. 
distribution $g(h)$, defined as follows

$\int_{h_{1}}^{h_{2}} g(h) d h=\frac{1}{R} A\left(h_{1}, h_{2}\right)$,

where $R$ denotes the total area of the region, and $A\left(h_{1}, h_{2}\right)$ is the area within region $\mathrm{R}$ covered by ice with thickness $h$ in the range $h_{1} \leq h<h_{2}$ (Thorndike et al., 1975).

Pack ice can be understood as being composed of three main ice types: level first-year ice (FYI), level multi-year ice (MYI), and deformed ice. In addition, the pack ice may contain areas of open water. Ice types cannot be separated unambiguously within an observed ice thickness distribution, since their thicknesses overlap. However, certain ice thickness categories are dominated by a particular ice type. FYI has undergone at most one growth/melt season, and on the basis of the model of Maykut and Untersteiner (1971) it can be assumed to reach a maximum of about $2 \mathrm{~m}$ at the end of the growth season, and about $1 \mathrm{~m}$ in the autumn after the summer melt, providing upper bounds on level FYI thickness at the time of annual maximum and minimum thickness. In the sea ice thickness distribution $g(h)$, ice thicker than level FYI consists of level MYI and deformed ice. The thickness of level MYI approaches the equilibrium thickness, which can be set as the upper limit for level MYI, i.e. 3-5 m depending on climatological conditions. Ice thicker than the equilibrium thickness is mostly deformed.

Ice thickness distributions in perennial ice zone (PIZ) and seasonal ice zone (SIZ) have distinct characteristics that vary seasonally. In the spring, $g(h)$ typically exhibits a pronounced peak corresponding to level FYI in the SIZ and level MYI in the PIZ. In the autumn, the PIZ thickness distribution can be bi-modal, if a second maximum is formed in open water or very thin ice. In the autumn SIZ, $g(h)$ is dominated by very thin FYI and open water, with low abundance of thicker ice types.

The evolution of $g(h)$ depends on the thermodynamic and dynamic forcing. Changes in those factors have different impacts on the shape of $g(h)$, and in some situations an evaluation of changes in $g(h)$ reveals whether the observed changes in the pack ice are due to predominantly thermodynamic or dynamic processes.

Ice growth and melt change the position of the modal peaks of level FYI and MYI. Pure thermodynamic forcing (in the case of landfast ice) would result in a single-peak distribution. Kurtosis, i.e. an indication of the peakedness of $g(h)$, is a measure of the relative contribution of dynamic processes (opening, redistribution, and advection of pack ice), which broaden the single-peak distribution. On a regional scale, changes in the circulation and influx of sea ice could result in large changes in $g(h)$. Shifts in differential ice drift have an effect on both ends of $g(h)$. Changes in lead opening are reflected in the fraction of open water and thin ice, and changes in ridging are seen in the tail of $g(h)$. However, sea ice thermodynamic and dynamic processes are strongly coupled, and in some situations it is difficult to separate these effects. For example, the longer the ice circulates in the Arctic, the more time it has to thicken both thermodynamically and through deformation. Thus, the change in the drift pattern and average travel time can cause significant changes both in the modal thickness and in the fraction of ridged ice.

In this study we utilize data from submarine cruises of the U.S Navy and the Royal Navy from the years 1975-2000. The data are archived and publicly available at US National Snow and Ice Data Center. The 26 years covered by the available data are divided into two periods, 1975-1987 and 1988-2000. The objective of the present paper is to examine changes of the sea ice draft distribution in detail. The analysis is conducted for spring and autumn, i.e. for the periods of annual maximum and minimum ice thickness. Particular attention is given to the analysis of changes in the composition of pack ice, and to the impact of thermodynamics and dynamics on the evolution of the Arctic sea ice cover. Changes in the ice dynamics are studied based on the IABP (International Arctic Buoy Program) ice drift observations.

The submarine sonar data have been examined in several earlier studies. However, many of these were limited to consider mean sea ice thickness or draft, e.g. Rothrock et al. (1999), Rothrock and Zhang (2005), Rothrock et al. (2008) and Kwok and Rothrock (2009). Only few studies (Wadhams and Davis, 2001; Yu et al., 2004) have presented the ice thickness distributions. In this paper we show ice thickness distributions for six regions, two seasons and two 13-year periods. Our results are based on the data from 31 submarine cruises, which is much more than used in previous studies; the number of cruises analyzed in the work of Wadhams and Davis (2001) is only 2, and in the work of Yu et al. (2004) the corresponding number is 7. In Wadhams and Davis (2001) analyses are regionally limited, covering the Greenland Sea and the Eurasian Basin. While the work of Tucker et al. (2001) is also based on submarine sonar measurements, they do not show changes in ice draft distributions other than relative fraction of four coarse ice draft classes. Our analysis extends prior work and provides a more detailed, quantitative view of changes in the Arctic sea ice thickness distribution.

\section{Data and analysis}

The US Navy and Royal Navy upward-looking sonar data set includes sea ice draft measurements from 37 cruises accomplished during the years 1975-2000, covering over $120000 \mathrm{~km}$ of track in total. Data are archived for public use at the US National Snow and Ice Data Center (NSIDC). Data has been recorded partly in analog, and partly in digital format. The error in the comparability of analog data with digitally recorded data is $\pm 6 \mathrm{~cm}$ (Wensnahan and Rothrock, 2005), which is very small compared with draft values of typically several meters, and in this study data collected in both formats have been used. The standard deviation of submarine sonar measurements is $25 \mathrm{~cm}$, and the draft 


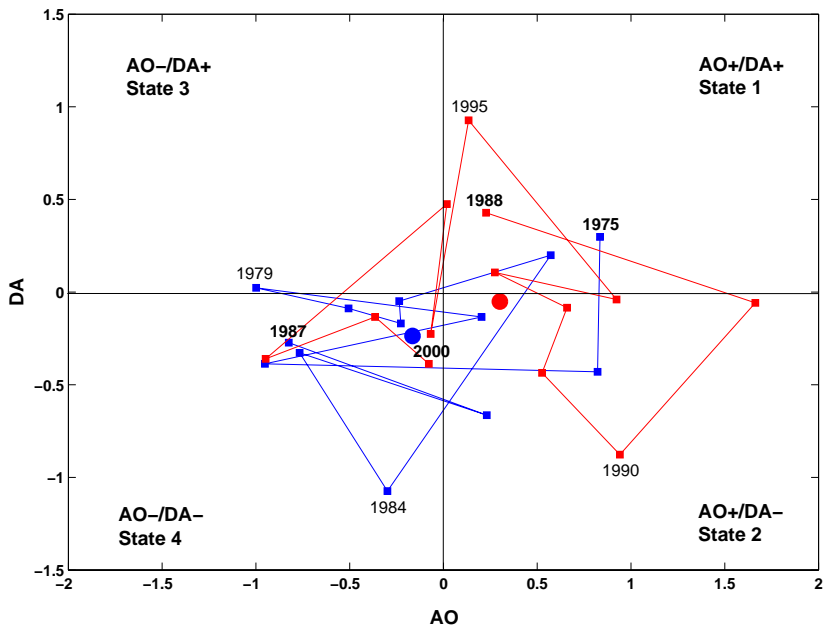

Fig. 1. Annual Arctic Oscillation index (AO) and Dipole Anomaly index (DA). Years 1975-1987 are marked with blue and years 1988-2000 with red color. Circles denote the mean values of these 13-year periods.

measurements are biased by $+29 \mathrm{~cm}$ compared with the true draft (Rothrock and Wensnahan, 2007). Very recent work of Rodrigues (2011) states that error of submarine based draft measurements depend on the measuring depth, beam width of the sonar and the roughness of ice bottom surface, and may be higher than reported in earlier studies. Unfortunately public archive in NSIDC does not include all the information needed (depth of a submarine, beam width) for data processing suggested by Rodrigues (2011). On the other hand, our results are now comparable with earlier works (e.g. Rothrock et al., 1999; Tucker et al., 2001; Yu et al., 2004). This study focuses on spring (April and May) and autumn (September and October), providing the highest data density, and the possibility to track annual maximum and minimum thicknesses (Rothrock et al., 1999). From here on, Spring refers to April and May, and Autumn refers to September and October. The cruises were equally distributed within each season during the whole study period, and no temporal adjustment is made for the date of the measurements.

The 26 years covered by the available data are divided into two periods, 1975-1987 and 1988-2000. Although the division is somewhat arbitrary, it coincides with changes in climatologic and oceanographic conditions in the Arctic, e.g. a decrease of sea level pressure (SLP) in the central Arctic at the end of the 1980s (Walsh et al., 1996), and a change in the AO index from a mostly negative to a strongly positive phase in 1988 (Rigor et al., 2002). As Wang et al. (2009) showed, the major atmospheric circulation patterns of the Arctic are well described by the modes of AO and DA. Figure 1 depicts how the individual years of the two periods examined in this paper are placed in an AO/DA space. It is clear that the period 1975-1987 was dominated by negative AO and DA years: average AO and DA values were -0.17 and
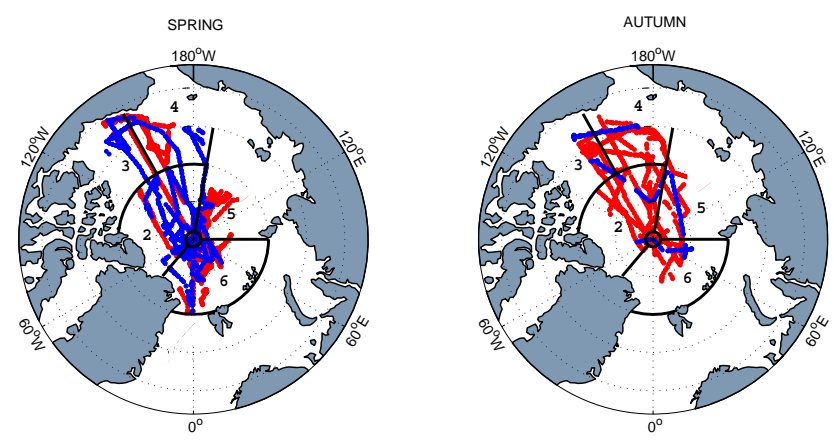

Fig. 2. Cruise tracks of utilized submarine data from periods 1975 1987 (blue) and 1988-2000 (red) in Spring (on the left) and Autumn (on the right). The whole study area is divided into 6 regions: 1 . North Pole, 2. Canada Basin, 3. Beaufort Sea, 4. Chukchi Sea, 5. Eastern Arctic and 6. Nansen Basin.

Table 1. Length of the submarine track in kilometers.

\begin{tabular}{lcccc}
\hline & \multicolumn{2}{c}{ Spring } & \multicolumn{2}{c}{ Autumn } \\
Region & $1975-1987$ & $1988-2000$ & $1975-1987$ & $1988-2000$ \\
\hline 1 North Pole & 1748 & 1836 & 86 & 1141 \\
2 Canada Basin & 5969 & 5411 & 296 & 6991 \\
3 Beaufort Sea & 3887 & 2355 & 368 & 4342 \\
4 Chukchi Sea & 1617 & 7128 & 316 & 7463 \\
5 Eastern Arctic & 376 & 5420 & 346 & 4682 \\
6 Nansen Basin & 4475 & 8593 & 306 & 2934 \\
\hline
\end{tabular}

-0.24 , respectively. The later period also includes negative AO and DA years, between 1996-2000, but positive AO and DA years prevailed at the beginning of the period.

In total, the former half (1975-1987) includes data from 12 cruises, of which 9 were accomplished in Spring and 3 in Autumn, while the later half (1988-2000) includes data from 11 Spring cruises and 8 Autumn cruises. To examine potential changes in regional variability, the covered area is divided into six regions (Fig. 2). As Fig. 2 shows, Spring cruise tracks provide better and more even coverage of all regions during both periods. In Autumn, especially in Chukchi Sea (region 4), data from the former period is collected in lower latitudes than data from latter period.

Analysis is based on profile data that includes all measurements at an interval of about one meter. Regional mean drafts and draft distributions are calculated from all the point measurements recorded within one region during the period and season concerned. In total the number of recordings utilized is over 78000000 , corresponding to roughly $78000 \mathrm{~km}$ of submarine track. The length of analyzed submarine track is listed in Table 1.

All analyses are based on and reported in terms of draft instead of thickness, because an accurate conversion to thickness would require knowledge of sea ice density, as well as 

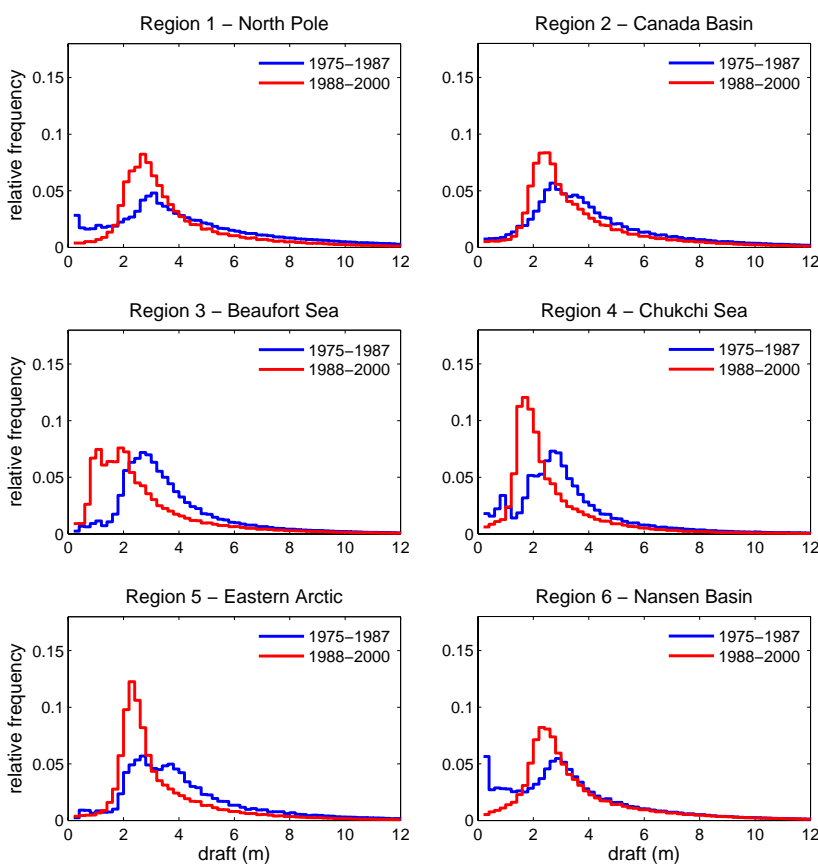

Fig. 3. Regional Spring draft distributions during periods 19751987 (blue line) and 1988-2000 (red line). Bin width $0.2 \mathrm{~m}$.

the thickness and the density of the snow cover. Mean draft values also include recordings of open water. The variability and changes of the Arctic sea ice cover are also examined through the evolution of three ice categories, classified by draft $(D)$. Category 1 includes all the ice with $D<2 \mathrm{~m}$ in Spring and $D<1 \mathrm{~m}$ in Autumn. Hence, this category consists mainly of level FYI. Category 2 is dominated by level MYI, and the upper limit is set at $D=5 \mathrm{~m}$. Category 3 consists of ice with draft $D>5 \mathrm{~m}$, and this category is dominated by deformed ice (Wadhams and Davis, 2001).

\section{Results}

\subsection{Ice draft distribution}

Probability density functions of ice draft, i.e. draft distributions $g(D)$ are calculated with an interval of $20 \mathrm{~cm}$ for each region, for Spring and Autumn in 1975-1987 and 1988-2000 (Figs. 3 and 4). Corresponding modal drafts are listed in Table 2. All regional Spring draft distributions from the first period (Fig. 3, blue line) have a uniform shape with one wide peak at draft 2-3 m, which falls into ice category 2 , and into the typical range of level MYI. Regional differences are most pronounced in the fraction of open water and thin ice, $D<0.5 \mathrm{~m}$. In region 6 the fraction of ice in the thinnest bin is so high that it results in a second maximum. Compared to the first period, Spring draft distributions from 1988-2000 (Fig. 3, red line) have much higher and narrower peaks, located in thinner ice, $D=1.5--2.5 \mathrm{~m}$, and their regional
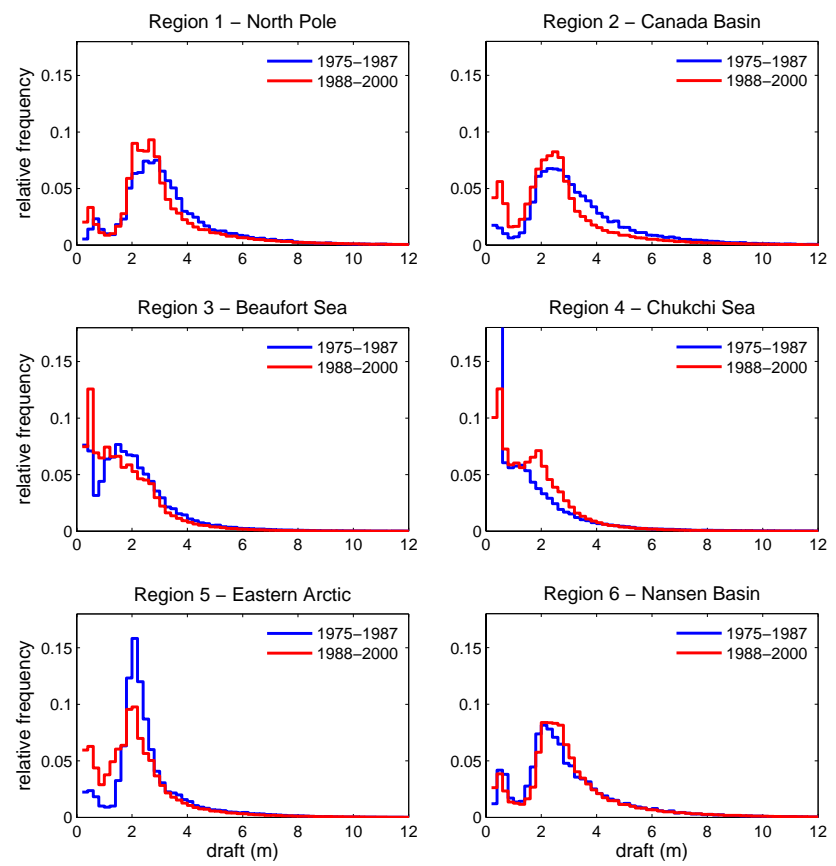

Fig. 4. Regional Autumn draft distributions during periods 19751987 (blue line) and 1988-2000 (red line). Bin width $0.2 \mathrm{~m}$.

variability is larger. In regions $1,2,5$ and 6 , i.e. in the central and eastern Arctic, Spring draft distributions show clear narrowing and heightening of the peak, due to a noticeable increase of ice with a draft of 1-3 $\mathrm{m}$ and a decrease of other thicknesses. In regions 1 and 2 modal draft in Spring is in MYI-dominated category 2 during both periods, despite a modest thinning $(-0.4 \mathrm{~m}$ and $-0.2 \mathrm{~m}$, respectively, Table 2$)$. In region 5 Spring modal draft has decreased from $2.5 \mathrm{~m}$ to $2.1 \mathrm{~m}$, but the shape of the peak has changed noticeably to a narrower and higher form. This is caused by an increase of ice with a draft of 1-3 m, and a clear decrease of ice with $D>3 \mathrm{~m}$. In the western Arctic, in regions 3 and 4, the modal draft in Spring has decreased from $2.5 \mathrm{~m}$ to $1.7 \mathrm{~m}$, and from $2.5 \mathrm{~m}$ to $1.5 \mathrm{~m}$, respectively. In these regions the peak has shifted from ice category 2 to category 1 . Although ice category 1 is assumed to be dominated by FYI, the increase in this category may be partly also due to the thinning of MYI cover. Eicken et al. (2001) observed in Chukchi Sea during the spring 1998 that the dominant ice type was level second year ice with the modal thickness less than $2 \mathrm{~m}$.

Autumn draft distributions from 1975-1987 (Fig. 4, blue line) differ clearly from Spring cases. The shape of Autumn draft distributions has a large regional variability. However, all the distributions, except region 4 , have a local minimum around $D=0.5-1 \mathrm{~m}$, at the boundary between level FYI and level MYI. Draft distributions from 1988-2000 (Fig. 4, red line) show a more pronounced bi-modal structure in the central Arctic (regions 1 and 2) as the concentration of thin FYI has increased, and the concentration of thick, mostly 
Table 2. Regional Spring and Autumn mean and modal draft in 1975-1987 and 1988-2000. The difference between regional mean drafts of these two periods is normalized over a decade.

\begin{tabular}{llccc}
\hline \multirow{2}{*}{ Region } & \multicolumn{4}{c}{ Mean/modal draft $(\mathrm{m})$} \\
& Season & $1975-1987$ & $1988-2000$ & Change (m/decade) \\
\hline \multirow{2}{*}{ 1 North Pole } & Spring & $4.4 / 2.9$ & $3.6 / 2.5$ & $-0.6 /-0.3$ \\
& Autumn & $3.1 / 2.7$ & $2.8 / 2.5$ & $-0.2 /-0.2$ \\
2 Canada Basin & Spring & $4.2 / 2.5$ & $3.4 / 2.3$ & $-0.6 /-0.2$ \\
& Autumn & $3.1 / 2.1$ & $2.4 / 2.3$ & $-0.6 /+0.2$ \\
3 Beaufort Sea & Spring & $3.5 / 2.5$ & $2.5 / 1.7$ & $-0.8 /-0.6$ \\
& Autumn & $1.7 / 1.3$ & $1.5 / 0.3$ & $-0.2 /-0.8$ \\
4 Chukchi Sea & Spring & $3.1 / 2.5$ & $2.4 / 1.5$ & $-0.5 /-0.8$ \\
& Autumn & $1.2 / 0.1$ & $1.4 / 0.3$ & $+0.2 /+0.2$ \\
5 Eastern Arctic & Spring & $4.5 / 2.5$ & $3.1 / 2.1$ & $-1.1 /-0.3$ \\
& Autumn & $2.3 / 1.9$ & $1.9 / 1.9$ & $-0.3 / 0$ \\
6 Nansen Basin & Spring & $3.3 / 0.1$ & $3.4 / 2.1$ & $+0.1 /+1.5$ \\
& Autumn & $2.7 / 1.9$ & $2.8 / 1.9$ & $+0.0 / 0$ \\
\hline
\end{tabular}

deformed ice has decreased. The concentration of very thin ice $(D<0.4 \mathrm{~m})$ has strongly increased in central Arctic: roughly doubled in region 1 and tripled in region 2 , resulting in a clear second maximum at $D=0.3 \mathrm{~m}$. Also ice with $D=1.5-2.5 \mathrm{~m}$ (mostly thin MYI) has increased in these two regions, while thicker ice has decreased. In Autumn the modal draft has remained unchanged in region 5. However, the shape of the draft distribution has changed from one high peak to a clearly bi-modal structure, as the fraction of open water and thin ice with $D<0.4 \mathrm{~m}$ has more than doubled, and the fraction of ice around $D=2 \mathrm{~m}$ (mainly level MYI) has decreased by nearly $40 \%$. In region 6, in Autumn, the draft distributions from periods 1975-1987 and 1988-2000 are very similar. In general, changes in the modal draft are smaller in Autumn than in Spring, and region 3 is the only region showing a strong decrease $(-1.0 \mathrm{~m})$ while in regions 2 and 4 the modal draft has increased by $0.2 \mathrm{~m}$ (Table 2). In Chukchi Sea this increase may be at least partly due to difference in sampling latitude, as the data from the earlier period derives from only the southern part of the region (Fig. 2).

Draft distributions can be divided into two groups with the characteristics of the PIZ and SIZ. In the PIZ the Autumn draft distribution typically has a bi-modal shape, with a modal draft in MYI and a second maximum in very thin ice or open water. As Fig. 4 shows, this is the case in regions 1, 2, 5 and 6 during both periods, and in region 3 during the first period. In these regions the modal draft is around $2-3 \mathrm{~m}$, the second maximum is in very thin ice $(D=0.3 \mathrm{~m})$, and there is a local minimum between them at $D=0.7-0.9 \mathrm{~m}$. In the SIZ the Autumn draft distribution is dominated by open water and thin FYI, which is the case in region 4 during both periods and in region 3 during the later period. In these regions the draft distributions do not show any distinguishable minimum between FYI and MYI, since the distribution is high and fairly even for drafts $0.5-2 \mathrm{~m}$, and the concentration of ice thicker than $D=2 \mathrm{~m}$ decreases rapidly with increasing draft.

In region 3 , the characteristics of the ice cover have clearly changed. The height and the width of the peak in the Spring draft distribution have remained the same, but the location has shifted to much thinner ice, from ice category 2 to category 1. As mentioned earlier, this strong increase in ice category 1 may be at least partly due to the thinning of level MYI cover. In Autumn, the change is most pronounced in thin ice $(D<0.6 \mathrm{~m})$, which has increased so much that a local minimum around $0.5 \mathrm{~m}$, present in 1975-1987, has disappeared. During the first period the shape of the Autumn draft distribution in region 3 has the characteristics of the PIZ, in contrast to the later period, when the shape of the Autumn draft distribution is very representative of the SIZ.

The regional Spring and Autumn mean drafts for the periods 1975-1987 and 1988-2000 are presented in Table 2. Table 2 also shows the difference between regional mean drafts for these two periods normalized over a decade. In Spring, in regions 3 and 5 the mean draft has noticeably decreased, by about $1 \mathrm{~m}$. In regions 1,2 and 4 the Spring mean draft also has clearly decreased, by $0.7 \mathrm{~m}$ or more. In Autumn, changes in general are more modest, and region 2 is the only region where the decline in the Autumn mean draft exceeds the thinning in Spring. In regions 1, 3 and 5, the decrease of the Autumn mean draft is only about $30 \%$ of the decrease observed in Spring. In region 4 the Autumn mean draft has increased by $0.2 \mathrm{~m}$. In region 6 the mean draft has remained nearly unchanged in both Spring and Autumn, with a slight increase of about $0.1 \mathrm{~m}$. However, in view of the accuracy of the draft measurements, changes with a magnitude of $0.1 \mathrm{~m}$ cannot be regarded as significant. 
Table 3. Difference in the mean ice draft and in the volume of three ice categories between the periods 1975-1987 and 1988-2000. Ice category 1 consists of ice with draft $<2 \mathrm{~m}$ in Spring and $<1 \mathrm{~m}$ in Autumn, ice category 2 includes draft range $2-5 \mathrm{~m}$ in Spring and $1-5 \mathrm{~m}$ in Autumn, and all ice with draft $>5 \mathrm{~m}$ falls into ice category 3 .

\begin{tabular}{|c|c|c|c|c|c|}
\hline Region & Season & Mean draft & category 1 & category 2 & category 3 \\
\hline \multirow[t]{2}{*}{1 North Pole } & Spring & $-18.2 \%$ & $+17.4 \%$ & $+27.5 \%$ & $-46.4 \%$ \\
\hline & Autumn & $-9.9 \%$ & $+8.0 \%$ & $-9.0 \%$ & $-12.8 \%$ \\
\hline \multirow[t]{2}{*}{2 Canada Basin } & Spring & $-16.9 \%$ & $+68.0 \%$ & $-3.5 \%$ & $-35.6 \%$ \\
\hline & Autumn & $-24.1 \%$ & $+1950.3 \%$ & $-17.6 \%$ & $-43.5 \%$ \\
\hline \multirow[t]{2}{*}{3 Beaufort Sea } & Spring & $-29.3 \%$ & $+176.4 \%$ & $-48.8 \%$ & $-35.7 \%$ \\
\hline & Autumn & $-16.8 \%$ & $+44.9 \%$ & $-19.5 \%$ & $-35.4 \%$ \\
\hline \multirow[t]{2}{*}{4 Chukchi Sea } & Spring & $-22.6 \%$ & $+134.3 \%$ & $-40.1 \%$ & $-44.1 \%$ \\
\hline & Autumn & $+19.0 \%$ & $-9.8 \%$ & $+43.6 \%$ & $-32.8 \%$ \\
\hline \multirow[t]{2}{*}{5 Eastern Arctic } & Spring & $-30.9 \%$ & $+109 \%$ & $-27.9 \%$ & $-47.1 \%$ \\
\hline & Autumn & $-16.6 \%$ & $+209.8 \%$ & $-20.5 \%$ & $-16.6 \%$ \\
\hline \multirow[t]{2}{*}{6 Nansen Basin } & Spring & $+3.3 \%$ & $+21.6 \%$ & $+10.3 \%$ & $-7.2 \%$ \\
\hline & Autumn & $+2.1 \%$ & $-17.3 \%$ & $+3.5 \%$ & $+0.3 \%$ \\
\hline
\end{tabular}
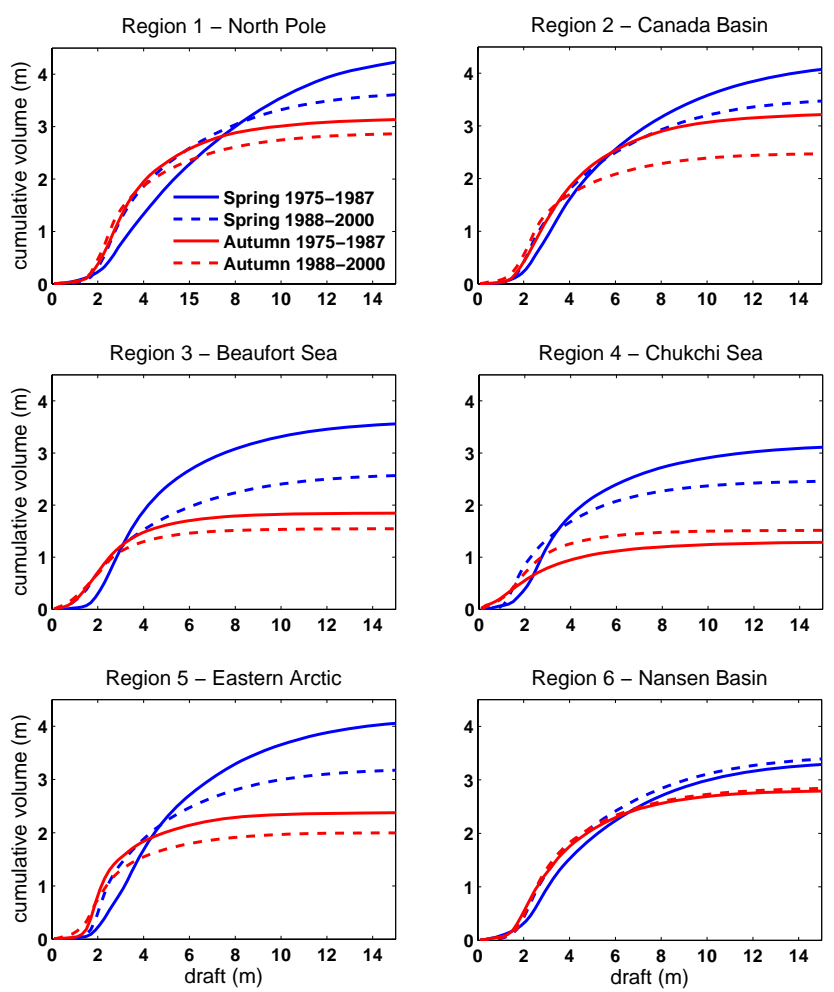

Fig. 5. Regional cumulative ice volume distribution in Spring and Autumn during the periods 1975-1987 and 1988-2000. Bin width $0.2 \mathrm{~m}$. Integration of ice volume distribution results in mean ice draft, which corresponds to ice volume over unit area.

\subsection{Ice volume distribution and composition of ice volume}

The probability density function of ice volume is calculated after Yu et al. (2004), but as a function of draft $D, V(D)=$ $g(D) D$. This function is dimensionless and describes the fraction of total volume of ice with draft $D$. It integrates to the mean draft (Yu et al., 2004)

$\bar{D}=\int_{0}^{\infty} V(D) d D$

and corresponds to a volume over a unit area. Because they are defined using draft instead of thickness, the volumes presented here correspond to the submerged portion of the total ice volume. As Eq. 2 shows, the total ice volume per unit area equals the mean draft, but the benefit of this approach as compared with calculating the mean draft by directly averaging single measurements is that it makes it possible to determine the composition of the total ice volume.

Cumulative ice volume distributions from the periods 1975-1987 and 1988-2000 in all the regions are shown in Fig. 5 for Spring and Autumn. The total ice volume per unit area, i.e. mean ice draft, is determined as the sum of the volumes in each bin, i.e. the cumulative volume in the thickest ice bin. Percentage changes in the mean ice draft in Spring and Autumn are listed in Table 3.

Region 6 is the only area where the mean ice draft has remained nearly unchanged in both seasons; it even shows a very slight increase. In all other regions the mean Spring ice draft has decreased by over $15 \%$, resulting from the loss of thick ice. The reduction of the mean Spring ice draft is largest in region 3 , where the decline is nearly $30 \%$ due to a considerable reduction of ice with $D>3 \mathrm{~m}$. At the same time, the volume of level FYI $(D<2 \mathrm{~m})$ is nearly twice as 
large during the later period. In region 4, the evolution of the mean ice draft in Spring is very similar to region 3, but in the central Arctic (regions 1 and 2) the decline is more modest $(-18 \%$ and $-17 \%$, respectively) and has occurred due to the loss of thicker, mostly deformed ice (with $D>8 \mathrm{~m}$ and $D>$ $5 \mathrm{~m}$, respectively).

In Autumn the change in the mean ice draft is largest in region $2(-24 \%)$, which is the only region where the decline is greater in Autumn than in Spring. Evolution in Autumn is exceptional in region 4 , where the mean ice draft has increased by $19 \%$, and the increase of ice volume is pronounced in all ice categories with $D>1 \mathrm{~m}$. However, this may be a result of the earlier data having been collected further south than the later data.

In addition to these changes in mean draft, the composition of the ice volume has also changed, even in region 6. Figure 6 illustrates the composition of the regional Spring and Autumn ice volumes of the three ice categories during both 13-year periods. The percentage change in the volume of the ice categories is listed in Table 3.

As Table 3 shows, the volume of ice category 1 has increased considerably in most of the regions and in both seasons. The only exceptions with decreasing volume of the thinnest ice category are regions 4 and 6 in autumn. Despite the clear increase in volume of ice category 1 , this thinnest ice category comprises less than $10 \%$ of the total ice volume in the PIZ (regions 1, 2, 5 and 6 during both periods, region 3 during former period). The change from perennial to seasonal ice in region 3 is evident in the remarkable increase of ice volume in category $1(+176 \%$ in Spring and $+45 \%$ in Autumn). Because of this large increase, during the later period about $25 \%$ of the total Spring ice volume consists of ice of the thinnest category, while during the former period the corresponding fraction is only $7 \%$.

The volume of MYI-dominated category 2 has generally decreased. The reduction has been strongest in region 3 ( $-49 \%$ in Spring and $-20 \%$ in Autumn) and in region 5 $(-28 \%$ and $-21 \%)$. In these regions the volume of ice in categories 1 and 2 (roughly representing the volume of level ice) has decreased in both seasons despite the increasing volume of the thinnest ice type (mainly thin FYI). In Spring a similar evolution, though of smaller magnitude, can be seen also in region 4 . In region 1 the volume of ice in category 2 in Spring has increased by more than $27 \%$. Even though ice of category 2 can be assumed to be dominated by level MYI, this increase does not necessarily mean an increase in level MYI volume. It can, and most likely does, reflect a decrease in the thickness of deformed ice, with a greater proportion of thin deformed ice falling into ice category $2(D<5 \mathrm{~m})$. In Autumn region 4 is the only region where a clear increase in the volume of ice in category 2 is observed. In region 6 changes are small, but in all other regions the volume of ice in category 2 in Autumn has decreased by about 10-20\%.

Ice in category 3 consists mostly of thick deformed ice. Evolution of this ice category is regionally and seasonally
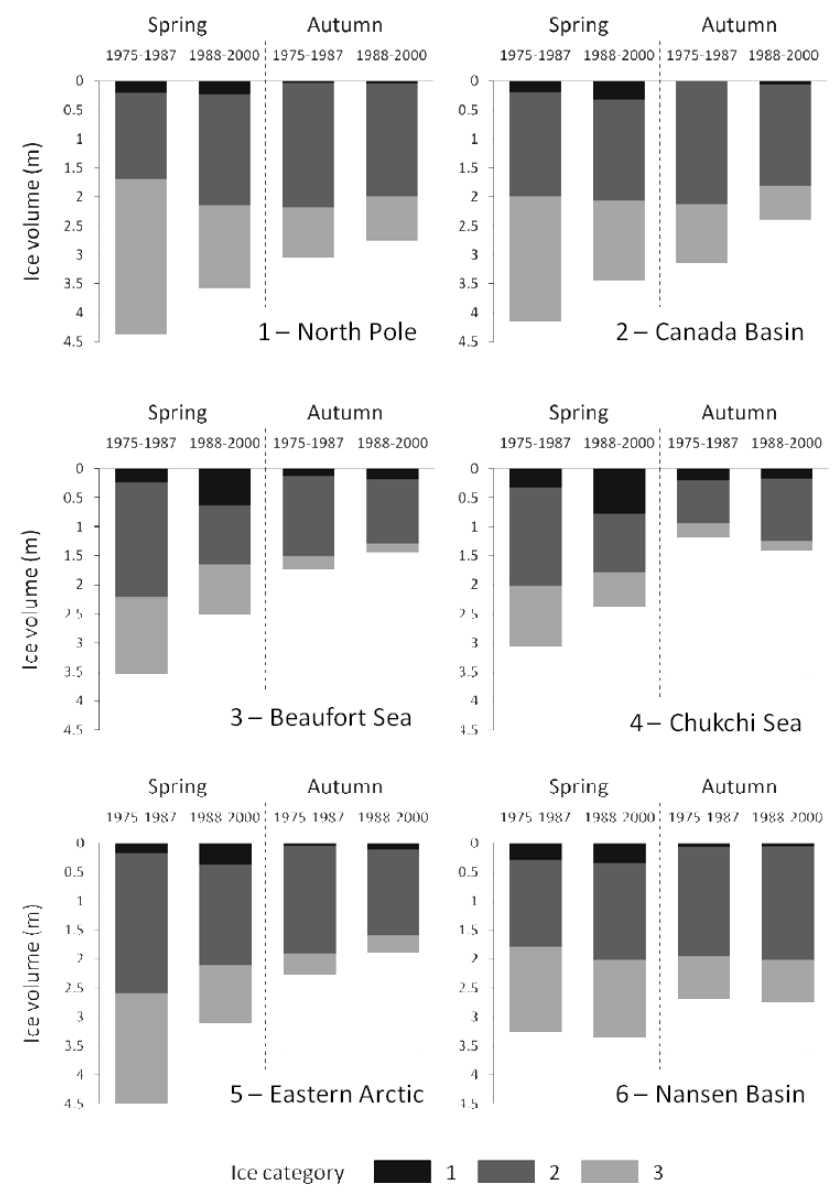

Fig. 6. Regional mean sea ice draft and its composition. Ice category 1 consists of ice with draft $<2 \mathrm{~m}$ in Spring and $<1 \mathrm{~m}$ in Autumn, ice category 2 includes draft range $2-5 \mathrm{~m}$ in Spring and 1$5 \mathrm{~m}$ in Autumn, and all ice with draft $>5 \mathrm{~m}$ falls into ice category 3.

the most uniform of all the observed changes. As draft distributions show, the concentration of thick deformed ice has decreased in all regions both in Spring and in Autumn. Since the thickest ice types have a great weight in the total ice volume, the decrease in the concentration of deformed ice is largely responsible for the decline in the mean ice draft that is observed in almost all the regions. In general, the volume of the thickest ice category has decreased more strongly in Spring than in Autumn, and only in region 2 we observe a greater decrease in Autumn than in Spring. In Spring the loss of category 3 ice volume exceeds $35 \%$ in all regions except region 6 , and the reduction reaches over $45 \%$ in regions 1 and 5. In Autumn the volume of thick, mostly deformed ice (category 3 ) has decreased by more than $40 \%$ in region 2 only, but the reduction is more than $30 \%$ also in regions 3 and 4. In Region 6 changes have been considerably smaller than in all other regions, $-7 \%$ in Spring and no change in Autumn. 
Figure 6 as well as Fig. 5 confirm that the loss of thick, deformed ice is largely responsible for the decrease in mean ice draft. This is most evident during Spring in regions 1 and 2, where the volume of ice categories 1 and 2 (roughly corresponding to level ice) has even increased, and thus the decline in the mean ice draft of over $17 \%$ has occurred purely due to the loss in the thickest ice category dominated by deformed ice. However, if the loss of deformed ice volume is not due to a decrease in the number of ice ridges only, but also due to a decreasing ridge thickness, then more deformed ice may fall into ice category 2 .

\section{Discussion}

\subsection{Thinning rate}

Regional mean drafts (Table 2) have decreased considerably in most regions, but with large regional and seasonal differences. Thinning of the Arctic sea ice cover has been reported in several studies (e.g. Wadhams, 1990; Rothrock et al., 1999; Wadhams and Davis, 2000; Tucker et al., 2001; Rothrock et al., 2003; Yu et al., 2004; Kwok and Rothrock, 2009). These studies are based on submarine sonar measurements, but from different years and seasons as well as from different areas, so that comparison of results is not straightforward. In all previous studies, as well as in our work, the observed thinning follows a similar regional pattern, with the largest changes in the central and western Arctic. These regions have been included in most of the past studies and exhibit the highest data densities. In other regions, results are more variable between studies and based on more sparse data.

Rothrock et al. (1999) and Yu et al. (2004) compared Autumn mean drafts from four historical submarine cruises (from late 1950s to 1970s) with three more recent voyages (1993-1997). They both reported pronounced ice thinning in the central and western Arctic, i.e. in the North Pole region, the Canada Basin and the Beaufort Sea, with a rate of approximately $-0.4 \mathrm{~m}$ per decade. This is about double the Autumn thinning rate in the North Pole region and the Beaufort Sea (regions 1 and 3) that we present in Table 2, but slightly less than that observed in the Canada Basin (region 2). Rothrock et al. (1999) reported strong thinning also in the Chukchi Sea, while Yu et al. (2004) did not find any significant change in this region. Both of these findings differ from the changes found in the present study, since for the period 1975-2000 the Chukchi Sea (region 4) shows an increase in Autumn mean draft with a rate of $+0.2 \mathrm{~m}$ per decade. In the Eastern Arctic the thinning rates observed by Rothrock et al. (1999) and Yu et al. (2004) differ from each other (-0.6 and $-0.1 \mathrm{~m}$ per decade, respectively), and the rate observed in the present study ( $-0.3 \mathrm{~m}$ per decade) lies between them. Comparison of the years 1958-1970 and 1993-1997 in (Rothrock et al., 1999) showed that the Nansen Basin, together with the Eastern Arctic, is the region of strongest thinning, while the present study covering the years 1975-2000 does not show any significant change in the region.

On the other hand, Wadhams (1990) and Wadhams and Davis (2000) observed strong thinning in the Nansen Basin also between the years 1976 and 1996. These studies are based on data not included in the NSIDC archive, and the cruise tracks extended further south than any of the Autumn cruises utilized in the present study. Wadhams and Davis (2000) observed the strongest thinning rates in the southernmost part, between latitudes $81^{\circ} \mathrm{N}-83^{\circ} \mathrm{N}$, where the mean draft in 1996 was only about $30 \%$ of the mean in 1976 . At latitudes of better data coverage Wadhams and Davis (2000) reported thinning rates clearly larger than those presented here. The explanation for this significant difference is most likely linked to the spatial and temporal averaging method. Wadhams and Davis (2000) compared data from two cruises in a very narrow sector, while the present study considers a larger area and two 13-year periods. On the basis of earlier observations of thinning in the same region (Wadhams, 1990), Wadhams and Davis (2000) concluded that a substantial part of the thinning took place before 1986, during a period not well covered in the Autumn data set of NSIDC.

Tucker et al. (2001) have also examined changes in the mean draft on the basis of submarine sonar data, but in contrast to Rothrock et al. (1999), Yu et al. (2004), Wadhams (1990) and Wadhams and Davis (2000) they used data from Spring cruises. For the period 1986-1994 Tucker et al. (2001) observed substantial thinning in the western Arctic (about $-1 \mathrm{~m}$ per decade) but the change in the North Pole region was insignificant. The longer time period considered in our analyses reveals smaller thinning rates in the Beaufort Sea and the Canada Basin $(-0.8$ and $-0.6 \mathrm{~m}$ per decade, respectively), but in the North Pole region the situation is the opposite, and the longer time period shows much stronger thinning $(-0.6 \mathrm{~m}$ per decade) than reported by Tucker et al. (2001).

The pronounced thinning in the western and central Arctic, with high initial ice thickness, has led to a decline in regional variability, and to a more uniform distribution of sea ice mass over the Arctic Ocean. A similar spatial pattern has also been observed in several model studies (e.g. Zhang et al., 2000; Bitz and Roe, 2004). In addition to the regional variation, the thinning rates presented in Table 2 also differ considerably between seasons. The thinning has generally been larger in Spring than in Autumn, implying a reduction in net ice growth over the course of the winter. Earlier analyses of submarine sonar measurements have focused on one season only, and therefore they have excluded the seasonal aspect of the thinning rate. Changes in the seasonal variability have not been much discussed in model studies, either. However, it must be taken into account that, as Bitz and Roe (2004) showed, the response of ice to the changing surface air temperature (SAT) depends on the initial thickness, and thus a small increase of SAT in the areas, and during the seasons, of thickest ice can cause a large decline in thickness. 
Table 4. Fractional volume of the ice in category 3 defined using two different draft limits, $D>3.5 \mathrm{~m}$ and $D>5 \mathrm{~m}$, in Spring and in Autumn during the periods 1975-1987 and 1988-2000, and the percentage change of the volume between the periods.

\begin{tabular}{rlcccccc}
\hline & & \multicolumn{2}{c}{$1975-1987$} & \multicolumn{2}{c}{$1988-2000$} & \multicolumn{2}{c}{ Change } \\
& $D>$ & $3.5 \mathrm{~m}$ & $5 \mathrm{~m}$ & $3.5 \mathrm{~m}$ & $5 \mathrm{~m}$ & $3.5 \mathrm{~m}$ & $5 \mathrm{~m}$ \\
\hline \multirow{2}{*}{ North Pole } & Spring & $79.4 \%$ & $61.2 \%$ & $60.0 \%$ & $40.1 \%$ & $-38.2 \%$ & $-46.4 \%$ \\
& Autumn & $50.2 \%$ & $28.5 \%$ & $44.8 \%$ & $27.6 \%$ & $-19.6 \%$ & $-12.8 \%$ \\
Canada Basin & Spring & $73.9 \%$ & $51.9 \%$ & $59.9 \%$ & $40.2 \%$ & $-32.7 \%$ & $-35.7 \%$ \\
& Autumn & $55.8 \%$ & $32.5 \%$ & $40.6 \%$ & $24.2 \%$ & $-44.8 \%$ & $-43.5 \%$ \\
Beaufort Sea & Spring & $60.7 \%$ & $37.4 \%$ & $50.3 \%$ & $34.0 \%$ & $-41.4 \%$ & $-35.7 \%$ \\
& Autumn & $29.0 \%$ & $13.6 \%$ & $23.8 \%$ & $10.6 \%$ & $-31.7 \%$ & $-35.4 \%$ \\
Chukchi Sea & Spring & $54.4 \%$ & $33.9 \%$ & $40.9 \%$ & $24.5 \%$ & $-41.8 \%$ & $-44.1 \%$ \\
& Autumn & $35.9 \%$ & $20.7 \%$ & $24.4 \%$ & $11.7 \%$ & $-19.1 \%$ & $-32.8 \%$ \\
Eastern Arctic & Spring & $65.6 \%$ & $42.6 \%$ & $51.1 \%$ & $32.6 \%$ & $-46.2 \%$ & $-47.1 \%$ \\
& Autumn & $30.9 \%$ & $16.7 \%$ & $30.2 \%$ & $16.7 \%$ & $-18.5 \%$ & $-16.6 \%$ \\
Nansen Basin & Spring & $65.6 \%$ & $45.3 \%$ & $58.6 \%$ & $40.7 \%$ & $-7.7 \%$ & $-7.2 \%$ \\
& Autumn & $48.6 \%$ & $28.0 \%$ & $46.6 \%$ & $27.5 \%$ & $-2.1 \%$ & $0.3 \%$ \\
\hline
\end{tabular}

\subsection{Composition of the ice cover}

In this study the three ice categories are classified by ice draft limits. The ice types (level FYI, level MYI and deformed ice) cannot be identified unambiguously by thickness only, because thickness ranges of different ice types are partly overlapping. In Fig. 6 and in Table 3, thickest ice category (category 3 ) consists of the ice with $D>5 \mathrm{~m}$. This limiting draft was chosen to be this high, near the upper bounce of Arctic equilibrium thickness, in order to ensure that the thickest category is dominated by deformed ice. Similar criteria have been applied e.g. in the work of Wadhams and Davis (2001), while Tucker et al. (2001) defined thickest, deformed ice category as $D>3.5 \mathrm{~m}$.

To study the sensitivity to the limiting draft value, we calculated the fractional volume and the volume change for ice category 3 using both $3.5 \mathrm{~m}$ and $5 \mathrm{~m}$ as the lower limit of the category. Table 4 shows that in most of the regions percentage changes in the volume of the thickest ice category do not vary much for different limiting draft values. Furthermore, the difference in the volume change does not exhibit any uniform pattern, i.e. in half of the regions and seasons the volume change is more pronounced for a smaller draft limit $(3.5 \mathrm{~m})$, while the opposite holds for the other regions. The biggest difference between the percentage volume change for different draft limits is in region 4 in Autumn, where the volume of ice with $D>3.5 \mathrm{~m}$ has decreased $19 \%$ and the volume of ice with $D>5 \mathrm{~m}$ shows a decrease of over $30 \%$. Apart from this, in most of the cases differences in ice volume changes are within 5 percentage points for the two different limiting drafts.

As described in the previous section, the thinning rates estimated in different studies vary considerably, even though many of them are based partly on the same data. However, all these studies are in close agreement concerning changes in the composition of ice volume, consistent with the results presented in this paper. E.g. Wadhams and Davis (2001), Tucker et al. (2001) and Yu et al. (2004) reported a clear decrease in the concentration and fractional volume of thick, mostly deformed ice. Our study also finds that the most substantial and seasonally and regionally most uniform of all changes is the loss of thick ice, evident in the draft distributions (Figs. 3-4) and even more so in the cumulative ice volume distributions (Fig. 5). From Fig. 5 it is evident that the decline in mean ice draft occurred due to the loss of thick ice, with some regional variation in the limiting draft.

Tucker et al. (2001) reported that in the Canada Basin (at $86^{\circ} \mathrm{N}$ ) the occurrence of deformed ice, which they defined as $D>3.5 \mathrm{~m}$, was reduced by $20 \%$ in the 1990 s compared to the 1980s. In the North Pole region, Tucker et al. (2001) did not find changes that strong, even though the concentration of FYI showed a slight increase, and the concentration of deformed ice showed a small decrease. Our analysis covers a longer time period and a larger area. In the Canada Basin our results are in very good agreement with Tucker et al. (2001). However, in the North Pole region the longer time period presented here reveals much larger changes than reported by Tucker et al. (2001).

The observation of a shift from a PIZ to a SIZ ice pack in the Beaufort Sea is supported by e.g. Comiso (2002). They observed significant year-to-year variation in the location of the PIZ, depending mostly on ice drift forced by atmospheric circulation, but also a clear reduction in the extent of perennial ice from 1978 to 2000. This reduction was most pronounced in the Beaufort and the Chukchi Seas, along with similar changes in the eastern part of the Arctic Ocean (Comiso, 2002). The ice volume increase in thin-ice categories is not necessarily due to FYI volume increases, but may be at least in part be due to thinning of MYI. 
Changes in the extent of Arctic sea ice, and especially in the extent of PIZ, have continued and even accelerated since 2000 (e.g. Maslanik et al., 2007; Comiso et al., 2008). Maslanik et al. (2007) point out that in addition to the retreat of the PIZ as a whole, the amount of the oldest and thickest ice within the remaining MYI pack has decreased significantly. In the mid-1980s $35 \%$ of MYI consisted of ice about 2-3 years old, but by 2007 the corresponding fraction had increased up to nearly $60 \%$ (Maslanik et al., 2007). The decrease of the modal draft up to the year 2000 (Table 2), as well as the reduction of the volume of ice in category 2 (Table 3) reflects a similar change in the average age of the ice. Even though category 2 ice can be assumed to be dominated by MYI, changes in the ice volume in this category do not necessarily directly show a change of level MYI volume, since the thickness ranges of the ice types (FYI, MYI and deformed ice) are partly overlapping. Therefore, in the case of decreasing average ice ridge thickness, more and more deformed ice may fall into ice category 2. Similarly, decrease of the level MYI thickness may result in more MYI in ice category 1 .

\subsection{Atmospheric forcing}

Several studies have pointed out the connection between Arctic sea ice thickness and climate indices. The clear shift in the $\mathrm{AO}$ index from a mostly negative to a strongly positive phase in the late 1980s caused the weakening of the anticyclone around the Beaufort Sea, which was at least partly responsible for the observed thinning of Arctic Sea ice (Rigor et al., 2002). On the other hand, Lindsay and Zhang (2005) observed the strong thinning to continue after the AO index returned to near-normal conditions in the late 1990s. In addition to the AO index, variations of the DA index also have an effect on ice drift patterns, and Wu et al. (2006) state that the influence of the DA on winter sea ice motion is greater than that of the AO, especially in the central Arctic basin and north of Fram Strait. The positive phase of the DA includes a weakening of the Beaufort Gyre and a strengthening of the Transpolar Drift, which implies an increase in ice export through Fram Strait and enhanced ice import from the Laptev and East Siberian Seas to the central Arctic (Wu et al., 2006). The DA displays strong interannual variability, but it does not show any apparent trend. In any case, the time series of the DA shows several years of very high values from the late 1980s to the late 1990s (Wu et al., 2006).

Watanabe et al. (2006) studied the effect of different combinations $\mathrm{AO}$ and $\mathrm{DA}$ indices by defining four states: positive $\mathrm{AO}$ and positive DA (state 1), positive AO and negative DA (state 2), negative $\mathrm{AO}$ and positive DA (state 3 ), negative $\mathrm{AO}$ and negative DA (state 4). Watanabe et al. (2006) observed that the total sea ice export from the Arctic Ocean reaches a maximum in state 1 , and a minimum in state 4 . The record lows of summer sea ice extent have occurred in states 1 and 3 (Wang et al., 2009).
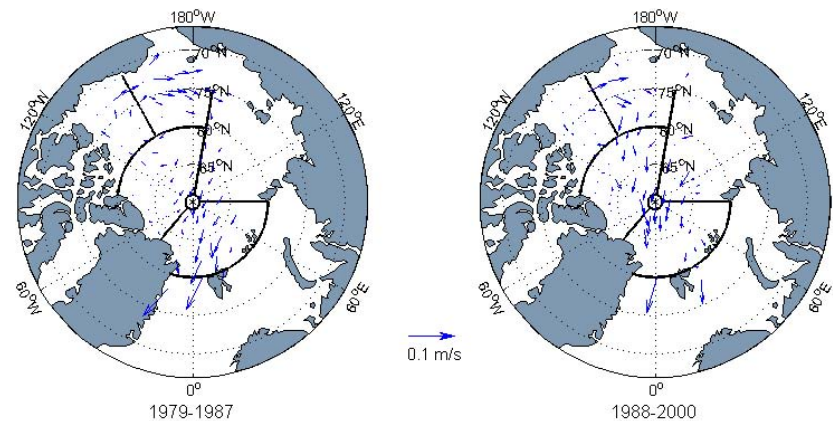

Fig. 7. Mean sea ice drift during the periods 1979-1987 and 19882000 .

As Fig. 1 shows, our study periods $1975-1987$ and 19882000 fall largely in different parts of the AO/DA space. During the first period more than half of the years fall in state 4, which is associated with very low ice export. During the later period the yearly values vary more, but most of the years are in state 1 or 2. A notable feature is that all the years of particularly high DA index values are in the later period (years 1988, 1995 and 1997) while very low DA index values are observed mostly in the first period. The AO index is more variable than DA, but as Watanabe et al. (2006) state, due to its strong meridionality DA seems to have a larger impact on the sea ice export than AO. This is supported by the variations in Arctic sea ice outflow through Fram Strait presented by Kwok (2009). The years of highest DA values (1988, $1995,1997)$ show up as peaks in the outflow time series, and the years of very low DA values (1984, 1986 and 1991) correspond to low ice export.

We use IABP buoy data to study the differences in sea ice drift during the two periods. Figure 7 shows the average sea ice motion in the Arctic Ocean during the periods 19791987 and 1988-2000. IABP operations started in 1979, 4 years later than submarine data used in this study and thus the years 1975-1978 are not included. From Fig. 7 it is evident that during the former period the Beaufort Gyre was much stronger and ice in the Transpolar Drift was originated in clearly more eastern parts of the Arctic than during the later period. Due to the westward shift of the Transpolar Drift, a large fraction of the ice entering Fram Strait drifted over the North Pole, originating from the western Arctic during the later period.

The pronounced thinning in the Eastern Arctic (region 5) can be explained by these changes in ice circulation patterns. In the later period, a larger proportion of the ice advected into this region comes from the Siberian coast, being thinner FYI. A region with a very different evolution, nearly unchanged ice conditions, is the Nansen Basin (region 6). There the influence of a change in the advection pattern is opposite, and it has balanced the effect of increased SAT, the lengthening of the melt season, and the possible increase of the oceanic heat flux. During the former period ice entering the Nansen Basin 
originated mostly from the SIZ of the Kara and Laptev Seas, while in the later period advection over the North Pole prevailed stronger, and included more thick ice from the central Arctic and the Beaufort Gyre. Since there are no significant changes in the ice draft distribution in the Nansen Basin, the increase of ice volume outflow in Fram Strait in the 1990s reported by Vinje (2001) has been largely due to increases in ice drift velocity, which is visible also in Fig. 7. In the western Arctic, the weakening of the Beaufort Gyre changes the dynamic forcing, resulting in a decrease in both the average age of the ice and the level of compression.

Comprehensive analysis of how the changes in the surface energy budget influence the ice thickness distribution is beyond the scope of the this paper. However, since the SAT is a result of the energy balance over sea ice, it can be used as a proxy of energy balance changes in wintertime. Figure 8 shows the difference in SAT between our two study periods, 1975-1987 and 1988-2000, calculated from ERA40 re-analyzed data (Uppala et al., 2005). Since our findings indicate seasonally uneven changes in the ice cover, the examination of SAT is conducted separately for the preceding months in both seasons concerned, i.e. for the growth season in winter (November-March, upper figure) and the melt season in summer (June-August, lower figure). In the winter, SAT shows substantial warming only over the land area in Siberia. Over the Arctic ocean, slight warming (less than $0.5^{\circ} \mathrm{C}$ ) is observed only in the region north of Greenland. Over the western Arctic, wintertime SAT has even decreased by $1{ }^{\circ} \mathrm{C}$. A simple thermodynamical ice growth model examination (Lepparanta, 1993) shows that $1^{\circ} \mathrm{C}$ difference in SAT during the six months ice growing period would result at maximum only about $5 \mathrm{~cm}$ difference at end of growth season and thus the surface energy balance changes in winter period appear to have only a modest impact.

In the summer, changes in SAT are negligible over the entire Arctic Ocean. This is expected, since as long as the ice cover prevails, SAT is bound to the melting point of ice due to an action of sensible heat flux. However, the length of the melt season has increased in the entire Arctic Ocean, including also the western parts (Belchansky et al., 2004a). Belchansky et al. (2004b) found a connection between the $\mathrm{AO}$ index and the length of the melt season. They observed an increase in melt season duration by up to 2-3 weeks, beginning in year 1989 and concurrent with a strong increase in the winter AO index. Hence, the second time period analyzed in this study is characterized by enhanced melt and reduced ice growth. Third important factor influencing the ice thickness growth rates, is snowfall. Unfortunately accurate measurements of snowfall during the study period are not available. However, Polyakov et al. (1999) stated that in the regime dominated by cyclonic circulation, which was the case during most of the period 1988-2000, precipitation over the Arctic Ocean is increased in all seasons. As described in Sect. 3, changes in the ice cover have been generally more pronounced in Spring than in Autumn. One possi-
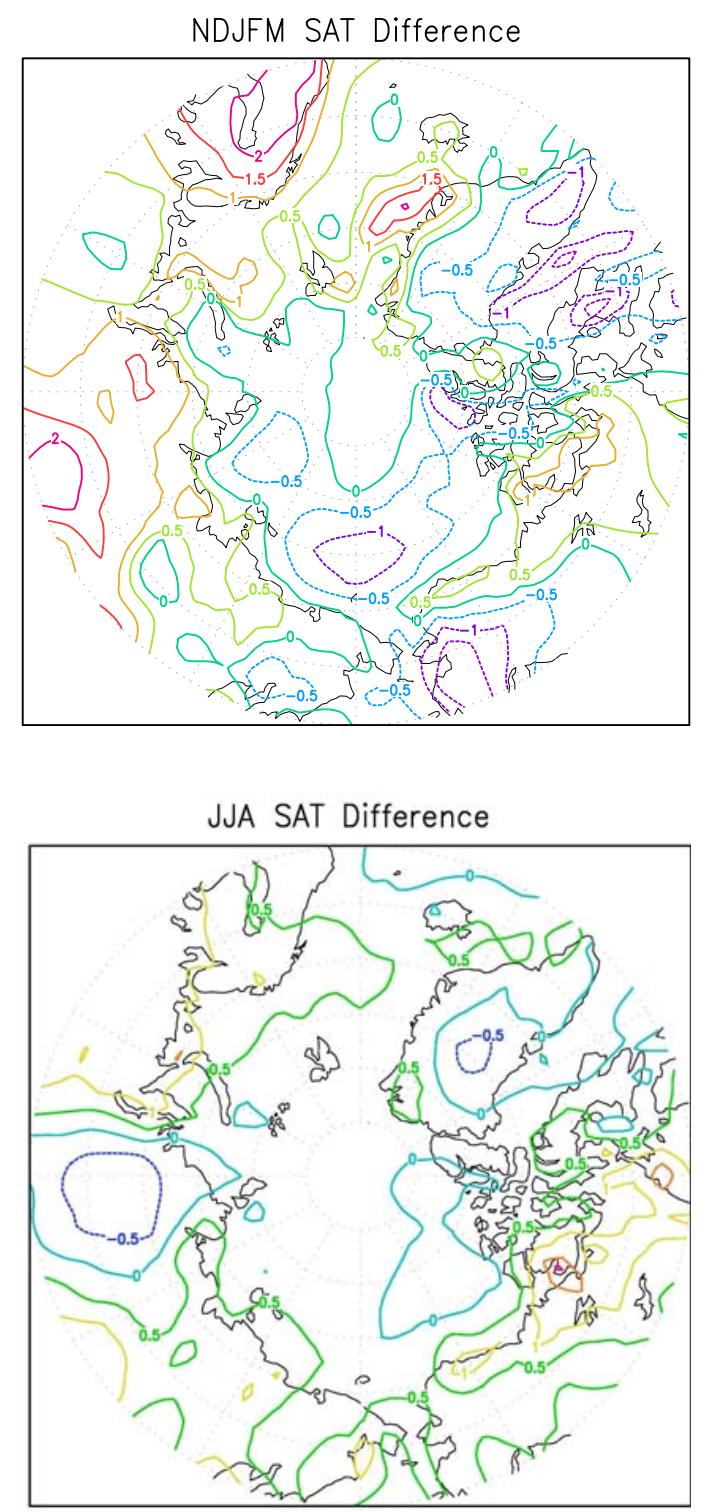

Fig. 8. Difference of surface air temperature between the periods 1975-1987 and 1988-2000. Winter months (November-March) are shown in the upper figure, and summer months (June-August) in lower figure.

ble explanation for this seasonality could be increased winter precipitation, since the ice thickness growth rate is effectively decreased by thickening of snow cover. In the summer the impact of increased precipitation would be opposite. Enhanced summer precipitation, if assumed to fall mostly as snow, would increase the surface albedo during the melting season and thus retard melting. 


\section{Conclusions}

In this paper we determine changes in Arctic ice draft distributions, mean and modal thicknesses, and their regional and seasonal variability under different large scale atmospheric circulation modes. We have compared characteristics of the Arctic pack ice during the periods 1975-1987 and 19882000, which have different distributions in the AO/DA space (Fig. 1).

A major finding of this study is that the shape of the sea ice draft distribution has changed: the peak of the ice draft distribution has generally narrowed and shifted toward thinner ice. A prevalent feature, apparent in all regions both in Spring and Autumn, is the loss of thick, mostly deformed ice, which has had an important impact on the decrease in the mean and modal ice thicknesses. In Spring the loss of the volume of ice thicker than $5 \mathrm{~m}$ exceeds $35 \%$ in all regions except the Nansen Basin, and the reduction is as much as $45 \%$ or more in the North Pole region and the Eastern Arctic. In Autumn the volume of thick, mostly deformed ice has decreased by over $40 \%$ in the Canada Basin, with a reduction of more than $30 \%$ in the Beaufort and the Chukchi Seas. Results also reveal a decrease in the seasonal variability of the mean ice thickness, but with strong regional differences. The regional variability of the sea ice thickness has decreased, since the thinning has been most pronounced in regions with formerly the thickest ice cover.

Ice dynamics have an essential impact on ice thickness and its distribution over the Arctic Ocean. Differences in the average ice motion during periods 1979-1987 and 1988-2000 clearly show the changes in the dynamic forcing. The shift in the drift pattern, mostly due to the weakening of the Beaufort Gyre, corresponds well with the observed strong thinning in the Beaufort Sea, the Canada Basin and the Eastern Arctic, and also with the unchanged thickness in the Nansen Basin. In the western Arctic, thinning due to dynamic forcing results from the decrease in the average ice age, and in the level of compression, while in the Eastern Arctic thinning may have been caused by the shift in advected ice source areas, leading to the dominance of SIZ on the Siberian coast. In the Nansen Basin, changes in ice advection balanced the influence of thermodynamics, as the origin of ice entering the region shifted from the dominance of seasonal ice in the Kara Sea and the Laptev Sea to a dominance of perennial ice around the North Pole.

Changes in the Arctic sea ice cover have continued and even accelerated during the last few years, as shown by the extreme minimum in ice extent recorded in September 2007 (Comiso et al., 2008). The changes in sea ice thickness characteristics described here, which occurred in the 1990s, have preconditioned the observed large decrease in the annual minimum sea ice extent. After year 2000 there have been a few submarine cruises in the Arctic Ocean, but the data is not yet freely available. The data collected during these cruises will probably show even larger changes in the draft and volume distributions than presented in this study. Comparison of statistics from the 1990s with the recent measurements of sea ice thickness by an electromagnetic method (Haas et al., 2008, 2010) show that during the last years the peak of draft distributions has changed into an even narrower form, and shifted toward thinner ice in the North Pole region.

Acknowledgements. We want to acknowledge National Snow and Ice Data Center for providing submarine sonar data set and IABP for their buoy database. ECMWF is acknowledged for providing ERA-40 reanalyzed meteorological data. We also wish to thank Jia Wang for providing AO and DA time series. We acknowledge the anonymous reviewers, whose constructive comments and suggestions were very helpful in improving the paper. This study was funded through the EU FP7 project Damocles (Development Arctic Modelling and Observing Capabilities for Long-term environmental Studies). A. Oikkonen was also supported by Academy of Finland (project 11224121).

Edited by: H. Eicken

\section{References}

Belchansky, G., Douglas, D., and Platonov, N.: Duration of the Arctic Sea Ice Melt Season: Regional and Interannual Variability, 1979-2001, J. Climate, 17, 67-80, 2004a.

Belchansky, G. I., Douglas, D. C., Alpatsky, I. V., and Platonov, N. G.: Spatial and temporal multiyear sea ice distribution in the Arctic: A neural network analysis of SSM/I data, 1988-2001, J. Geophys. Res., 109, doi:10.1029/2004JC002388, 2004b.

Bitz, C. M. and Roe, G. H.: A mechanism for the high rate of sea ice thinning in the Arctic Ocean, J. Climate, 17, 3623-3632, 2004.

Comiso, J. C.: A rapidly declining perennial sea ice cover in the Arctic, Geophys. Res. Lett., 29, 1956, doi:10.1029/2002GL015650, 2002.

Comiso, J. C., Parkinson, C. L., Gersten, R., and Stock, L.: Accelerated decline in the Arctic sea ice cover, Geophys. Res. Lett., 35, doi:10.1029/2007GL031972, 2008.

Eicken, H., Tucker, W. B., and Perovich, D. K.: Indirect measurements of the mass balance of summer Arctic sea ice with an electromagnetic induction technique, Ann. Glaciol., 33, 194-200, 2001.

Haas, C., Pfaffling, A., Hendricks, S., Rabenstein, L., Etienne, J.-L., and Rigor, I.: Reduced ice thickness in Arctic Transpolar Drift favors rapid ice retreat, Geophys. Res. Lett., 1, doi:10.1029/2008GL034457, 2008.

Haas, C., Hendricks, S., Eicken, H., and Herber, A.: Synoptic airborne thickness surveys reveal state of Arctic sea ice cover, Geophys. Res. Lett., 37, doi:10.1029/2010GL042652, 2010.

Hilmer, M. and Lemke, P.: On the decrease of Arctic sea ice volume, Geophys. Res. Lett., 27, 3751-3754, 2000.

Holloway, G. and Sou, T.: Has Arctic sea ice rapidly thinned?, J. Climate, 15, 1691-1701, 2002.

Kwok, R.: Outflow of Arctic Ocean Sea Ice into the Greenland and Barents Seas: 1979-2007, J. Climate, 22, 2438-2457, 2009.

Kwok, R. and Rothrock, D. A.: Decline in Arctic sea ice thickness from submarine and ICESat records: 1958-2008, Geophys. Res. Lett., 36, doi:10.1029/2009GL039035, 2009. 
Lepparanta, M.: A review of analytical models of sea-ice growth, Atms. Ocean., 31, 123-138, 1993.

Lindsay, R. W. and Zhang, J.: The Thinning of Arctic Sea Ice, 19882003: Have We Passed a Tipping Point?, J. Climate, 18, 48794894, 2005.

Makshtas, A. P., Shoutilin, S. V., and Andreas, E. L.: Possible dynamic and thermal causes for the recent decrease in sea ice in the Arctic Basin, J. Geophys. Res., 108, doi:10.1029/2001JC000878, 2003.

Maslanik, J. A., Fowler, C., Stroeve, J., Drobot, S., Zwally, J., Yi, D., and Emery, W.: A younger, thinner ice cover: Increased potential for rapid, extensive sea-ice loss, Geophys. Res. Lett., 34, doi:10.1029/2007GL032043, 2007.

Maykut, G. A. and Untersteiner, N.: Some results from a timedependent thermodynamic model of sea ice, J. Geophys. Res., 76, 1550-1575, 1971.

NSIDC: National Snow and Ice Data Center, Submarine upward looking sonar ice draft profile data and statistics, 1998, updated 2006.

Polyakov, I. V., Proshutinsky, A. Y., and Johnson, M. A.: Seasonal cycle in two regimes of Arctic climate, J. Geophys. Res., 104, 25761-25788, 1999.

Rigor, I. G., Wallace, J. M., and Colony, R.: Response of sea ice to the Arctic Oscillation, J. Climate, 15, 2648-2663, 2002.

Rodrigues, J.: Beamwidth effects on sea ice draft measurements from U.K. submarines, Cold Reg. Sci. Technol., 65, 160-171, 2011.

Rothrock, D. A. and Wensnahan, M.: The accuracy of sea-ice draft measured from U.S. Navy submarines, J. Atmos. Ocean. Techn., 24, 1936-1949, 2007.

Rothrock, D. A. and Zhang, J.: Arctic ocean sea ice volume: What explains its recent depletion?, J. Geophys. Res., 110, doi:10.1029/2004JC002282, 2005.

Rothrock, D. A., Yu, Y., and Maykut, G. A.: Thinning of the Arctic sea-ice cover, Geophys. Res. Lett., 26, 3469-3472, 1999.

Rothrock, D. A., Zhang, J., and Yu, Y.: The arctic ice thickness anomaly of the 1990s: A consistent view from observations and models, J. Geophys. Res., 108, doi:10.1029/2001JC001208, 2003.

Rothrock, D. A., Percival, D. B., and Wensnahan, M.: The decline in arctic sea-ice thickness: Separating the spatial, annual and interannual variability in quarter century of submarine data, J. Geophys. Res., 113, doi:10.1029/2007JC004252, 2008.

Thompson, D. W. J. and Wallace, J. M.: The Arctic Oscillation signature in the wintertime geopotential height and temperature fields, Geophys. Res. Lett., 25, 1297-1300, 1998.

Thorndike, A. S., Rothrock, D. A., Maykut, G. A., and Colony, R.: The thickness distribution of sea ice, J. Geophys. Res., 80, 45014513, 1975.
Tucker, W. B., Weatherly, J. W., Eppler, D. T., Farmer, L. D., and Bentley, D. L.: Evidence of rapid thinning of sea ice in the western Arctic Ocean at the end of the 1980s, Geophys. Res. Lett., 28, 2851-2854, 2001.

Uppala, S. M., Kållberg, P. W., Simmons, A. J., Andrae, U., Da Costa Bechtold, V., Fiorino, M., Gibson, J. K., Haseler, J., Hernandez, A., Kelly, G. A., Li, X., Onogi, K., Saarinen, S., Sokka, N., Allan, R. P., Andersson, E., Arpe, K., Balmased, M. A., Beljaars, A. C. M., Van de Berg, L., Bidlot, J., Bormann, N., Caires, S., Chevallier, F., Dethof, A., Dragosavac, M., Fisher, M., Fuentes, M., Hagemann, S., Hólm, E., Hoskins, B. J., Isaksen, L., Janssen, P. A. E. M., Jenne, R., McNally, A. P., Mahfouf, J.-F., Morcrette, J.-J., Rayner, N. A., Saunders, R. W., Simon, P. and Sterl, A., Trenberth, K. E., Untch, A., Vasiljevic, D., Viterbo, P., and Woollen, J.: The ERA-40 re-analysis, Q. J. R. Meteorol. Soc., 131, 2961-3012, 2005.

Vinje, T.: Fram Strait ice fluxes and atmospheric circulaiton: 19502000, J. Climate, 14, 3508-3517, 2001.

Wadhams, P.: Evidence for thinning of the Arctic ice cover north of Greenland, Nature, 345, 795-797, 1990.

Wadhams, P. and Davis, N. R.: Further evidence of ice thinning in the Arctic Ocean, J. Geophys. Res., 27, 3973-3975, 2000.

Wadhams, P. and Davis, N. R.: Arctic sea-ice morphological characteristics in summer 1996, Ann. Glaciol., 33, 165-170, 2001.

Walsh, J. E., Chapman, W. L., and Shy, T. L.: Recent decrease of sea level pressure in the central Arctic, J. Climate, 9, 480-486, 1996.

Wang, J., Zhang, J., Watanabe, E., Ikeda, M., Mizobata, K., Walsh, J., Bai, X., and Wu, B.: Is the Dipole Anomaly a major driver to record lows in Arctic summer sea ice extent?, Geophys. Res. Lett., 36, doi:10.1029/2008GL036706, 2009.

Watanabe, E., Wang, J., Zhang, J., Sumi, A., and Hasumi, H.: Arctic dipole anomaly and its conttribution to sea ice export from the Arctic Ocean in the 20th century, Geophys. Res. Lett., 33, doi:10.1029/2006GL028112, 2006.

Wensnahan, M. and Rothrock, D. A.: Sea-ice draft from submarine-based sonar: Establishing a consistent record from analog and digitally recorded data, Geophys. Res. Lett., 32, doi:10.1029/2005GL022507, 2005.

Wu, B., Wang, J., and Walsh, J.: Dipole Anomaly in the winter Arctic atmosphere and its association with sea ice motion, J. Climate, 19, 210-225, 2006.

Yu, Y., Maykut, G. A., and Rothrock, D. A.: Changes in the thickness distribution of Arctic sea ice between 1958-1970 and 19931997, J. Geophys. Res., 109, doi:10.029/2003JC001982, 2004.

Zhang, J., Rothrock, D. A., and Steele, M.: Recent changes in Arctic sea ice: The interplay between ice dynamics and thermodynamics, J. Climate, 13, 3099-3114, 2000. 